\title{
Sequence analysis of a rice BAC covering the syntenous barley Rpgl region
}

\author{
F. Han, A. Kilian, J .P. Chen, D. Kudrna, B. Steffenson, K. Yamamoto, \\ T. Matsumoto, T. Sasaki, and A. Kleinhofs
}

\begin{abstract}
In the course of map-based cloning of the barley stem rust resistance gene Rpgl, we identified a rice bacterial artificial chromosome (BAC) containing the Rpgl flanking markers. Based on the excellent gene order colinearity between barley and rice in this region, we expected that this rice BAC would contain the barley Rpg1 homologue. In order to identify the putative rice homologue, we sequenced ca. $35 \mathrm{~kb}$ of the rice BAC at random and then an additional $33 \mathrm{~kb}$ of contiguous sequence between the two most closely spaced Rpg1 flanking markers. Sequence analysis revealed a total of 15 putative genes, 5 within the 33-kb contiguous region. A rice Rpgl homologue was not identified, although a gene encoding a hypothetical polypeptide with similarity to a membrane protein could not be eliminated as a candidate. Surprisingly, four of the genes identified in the 33-kb contiguous rice sequence showed a high degree of similarity with genes on Arabidopsis chromosome 4. The genome regions harboring these genes showed some relatedness, but many rearrangements were also evident. These data suggest that some genes have remained linked even over the long evolutionary separation of Arabidopsis and rice, as has also been reported for mammals and invertebrates.
\end{abstract}

Key words: genes, genome, rice, synteny, sequence.

Résumé : Au cours de travaux visant le clonage du gène Rpgl qui confère la résistance à la rouille des tiges chez l'orge, les auteurs ont identifié un chromosome artificiel bactérien (BAC) de riz contenant les marqueurs flanquant Rpg1. En raison de l'excellente conservation de l'ordre des gènes dans cette région entre l'orge et le riz, les auteurs s'attendaient à ce que ce BAC contienne l'homologue du gène Rpgl de l'orge. Afin d'identifier l'homologue potentiel chez le riz, les auteurs ont séquencé environ $35 \mathrm{~kb}$ du clone BAC de riz au hasard et un autre segment $33 \mathrm{~kb}$ de séquences contiguës situées entre les deux marqueurs flanquants les plus proches de Rpgl. L'analyse de ces séquences a révélé un total de 15 gènes potentiels dont cinq dans la région de $33 \mathrm{~kb}$ d'ADN contigu. Un homologue de Rpgl chez le riz n'a pu être identifié, bien qu'un gène codant pour un polypeptide hypothétique montrant de la similarité avec une protéine membranaire demeure un candidat possible. Étonnamment, quatre des gènes identifiés dans la région de $33 \mathrm{~kb}$ montrent une forte similarité avec des gènes situés sur le chromosome 4 d'Arabidopsis. Les régions génomiques contenant ces gènes montraient des similitudes, mais de nombreux réarrangements étaient également évidents. Ces données suggèrent que certains gènes sont demeurés liés sur de très longues périodes d'évolution telles que celle qui sépare l'Arabidopsis et le riz, comme cela a été rapporté chez les mammifères et les invertébrés.

Mots clés : gènes, génome, riz, synténie, séquence.

[Traduit par la Rédaction]

\section{Introduction}

The barley stem rust resistance gene, Rpg1, located near the telomere of the short arm of barley chromosome $1(7 \mathrm{H})$, has been our major target for map-based cloning. Although barley is an excellent organism for genetic studies, it poses a considerable challenge for map-based cloning because of its large genome size $\left(4.9 \times 10^{9} \mathrm{bp}\right.$, Arumuganathan and Earle

Corresponding Editor: G. Scoles.

Received March 16, 1999. Accepted June 1, 1999.

F. Han, ${ }^{1}$ J.P. Chen, ${ }^{2}$ D. Kudrna, and A. Kleinhofs. ${ }^{3}$ Departments of Crop and Soil Sciences, and Genetics and Cell Biology, Washington State University, Pullman, WA 99164-6420, U.S.A.

A. Kilian. Center for the Application of Molecular Biology to International Agriculture, GPO Box 3200, Canberra, ACT 2601, Australia.

B. Steffenson. Department of Plant Pathology, North Dakota State University, Fargo, ND 58105, U.S.A.

K. Yamamoto, T. Matsumoto, and T. Sasaki. Rice Genome Research Program, National Institute of Agrobiological ResourcesInstitute of Society for Techno-Innovation of Agriculture, Forestry and Fisheries, Tsukuba, Ibaraki 305, Japan.

${ }^{1}$ Current address: Pioneer Hi-Bred Intl. Inc., 7300 NW 62nd Ave., Johnston, IA 50131, U.S.A.

${ }^{2}$ Current address: Department of Plant Pathology, Washington State University, Pullman, WA 99164-6420, U.S.A.

${ }^{3}$ Author to whom all correspondence should be addressed (e-mail: andyk@wsu.edu). 
1991). Discovery of synteny (conservation of gene linkages) among several plant species has suggested the use of the genetic and physical resources of the small genome plants to facilitate map-based cloning in the large genome plants. A general synteny among major grass species has been documented (Devos and Gale 1997; Saghai Maroof et al. 1996) as well as microsynteny between specific regions of the rice and barley genomes, especially in the Rpgl region (Han et al. 1998; Kilian et al. 1997, 1995). Comparative sequence analyses of genomes also provides direct information about genome organization and evolution.

A rice bacterial artificial chromosome (BAC) containing the markers flanking the barley stem rust resistance gene Rpgl was previously characterized, demonstrating excellent microsynteny between rice and barley in this region (Kilian et al. 1997). In order to identify a putative rice $R p g 1$ homologue, we sequenced and analyzed this rice BAC clone. A rice Rpgl homologue was not identified, although a membrane protein-like gene, designated PG2, could not be eliminated as a candidate. Surprisingly, four of the five genes identified in the $33-\mathrm{kb}$ contiguous rice segment (including the two closest Rpgl flanking markers) showed a high degree of similarity with genes on Arabidopsis chromosome 4.

\section{Materials and methods}

\section{BAC DNA preparation and subcloning}

The isolation and subcloning of the rice BAC clone $10-\mathrm{N}-24$ including the markers flanking the Rpgl gene was previously reported (Kilian et al. 1997). Plasmid libraries were generated with the restriction enzymes BamHI, EagI, MluI, SalI, BamHI +EcoRI, and a contig with selected large insert clones was constructed.

\section{Sequencing}

Sequencing was performed using the Dye Terminator cycle sequencing kit (Perkin-Elmer) and an Applied Biosystems 373 DNA sequencer at the Bioanalytical Center, Washington State University, Pullman, Wash. Sequencing of rice cDNAs or ESTs was done at the Rice Genome Research Program (RGP), Institute of the Society for Techno-innovation of Agriculture, Forestry, and Fisheries (STAFF), Tsukuba, Japan.

\section{Genetic mapping}

High resolution genetic mapping in barley was performed with 3000 gametes. Fifteen hundred gametes are doubled haploid (DH) lines derived from the crosses: Steptoe $\times$ Morex, Harrington $\times$ Morex, Steptoe $\times$ Q21861, Dicktoo $\times$ Morex, and Q21861 × SM89010. The other 1500 gametes are represented by $F_{2}$ plants from a Steptoe $\times$ Q21861 cross. DH lines with recombination between the Rpgl flanking markers ABG704 and ABG077, and $\mathrm{F}_{2}$ plants with recombination between the flanking markers B118 (cosegregates with $\mathrm{ABG704}$ in a 150-gamete population) and ABG077 were identified and used for high resolution mapping.

\section{Phenotyping}

All recombinants were scored for resistance or susceptibility to the stem rust pathogen Puccinia graminis f.sp. tritici, pathotype MCC, as previously described (Kilian et al. 1994). For recombinant $\mathrm{F}_{2}$ plants, $15 \mathrm{~F}_{3}$ seedlings from each $\mathrm{F}_{2}$ plant were phenotyped as above, and the data were used to determine the Rpgl genotype in the $F_{2}$.

\section{Data analyses}

Sequencing data were assembled by GCG program supported by the VADMS (Visualization, Analysis and Design in the Molecular Sciences) center at Washington State University. Assembled DNA sequences were searched first for open reading frames (ORFs) by ORF FINDER, a program on the Home page of the National Center for Biotechnology Information (NCBI) (http:// www.ncbi.nlm.nih.gov:80/). The identified ORFs (amino acid sequence) were used to search data bases using the new BLAST program (Altschul et al. 1997) implemented also on the NCBI home page. The similarity score and $E$-value (probability of a chance similarity) for the unknown sequence are reported in the text. Repetitive sequences were identified by visual analysis and REPEATMASKER (http://ftp.genome.washington.edu/RM/RepeatMasker.html).

\section{Results}

Initially, we sequenced the rice BAC $10-\mathrm{N}-24$ subclones at random in order to identify a putative Rpgl candidate gene. A total of 125 subclones were sequenced and assembled into 43 contigs, yielding a 34728 - bp sequence. Data base searches identified 9 contigs containing 10 ORFs, which showed similarity to existing data base sequences (Table 1). The clones B106 and B156 are likely to be parts of the same gene since they show similarity to the same hypothetical protein gene in Arabidopsis. One interesting clone, B138, which showed strong homology to the cell division inhibitor gene MinD in Chlorella vulgaris, contained a perfect P-loop motif (GKGGVGKT). With the conservation of the P-loop in the class of NBS-LRR R genes, this clone was considered to be a potential candidate for Rpg1. However, genetic mapping placed B138 $1.3 \mathrm{cM}$ proximal to Rpgl (based on $150 \mathrm{ga}$ metes). Other putative genes also failed to cosegregate with Rpgl.

A systematic sequencing of the rice $\mathrm{BAC}$ region between the Rpgl flanking markers B122 to B24 was then undertaken to assure that the putative homologous gene was not missed. A detailed physical map was established, and sequencing was carried out using specific primers and subcloning of large insert plasmid clones. A total of 160 fragments were sequenced and assembled into a 33178 - bp contig, termed Bam33 contig. Detailed analyses of the Bam33 contig sequence identified five putative genes designated PG1-5 (Fig. 1). The PG1-4 translation products showed similarity with a hypothetical protein in Arabidopsis, a hypothetical membrane protein in Arabidopsis, a myb-related protein in Arabidopsis, and the product of Arabidopsis cDNA T20924, respectively (Table 1). The myb-related protein gene PG3 included the myb-like domain WTDPEQGQV with only one mismatch from the consensus sequence W[ST]XXE[DE]XX[LIV]. The PG4 sequence included the rice EST S1558. The PG5 sequence ORF encoded 317 amino acids that showed homology to a fertilin alpha subunit in Oryctolagus cuniculus. The probe isolated from the rice PG5 region hybridized strongly to a Southern blot containing a wide range of grass species, including barley, but data base searches did not identify an Arabidopsis homologue. Arabidopsis genes with high similarity to the rice genes PG1 and PG2 are on the same Arabidopsis BAC, ATFCA6. These two genes are ca. $16 \mathrm{~kb}$ apart and are translated in opposite directions, but with the same orientation in both species. Furthermore, the Arabidopsis genes with simi- 
larity to the rice genes PG3 and PG4 are on another Arabidopsis BAC, IG002N01, and are separated by a very short physical distance from each other $(1.5 \mathrm{~kb}$ in Arabidopsis and $0.5 \mathrm{~kb}$ in rice, Fig. 1). These two genes are also transcribed in opposite directions as well as in reverse orientations in the two species. These results suggest possible conservation of gene order and spacing between these gene pairs in rice and Arabidopsis.

Short di- and trinucleotide repeats were found dispersed throughout the 33-kb sequence, especially in the intergenic regions. Two sequence repeats are noteworthy. A 281-bp sequence (from 9939 to $10220 \mathrm{bp}$ ) was tandemly repeated in the ca. 14-kb sequence between PG1 and PG5 with only 10 base changes and 1 addition or deletion. It is possible that this repeat represents the long terminal repeats of an ancient transposon. A short inverted repeat, $(\mathrm{GAA})_{4}$ and (TTC) $)_{4}$ separated by $233 \mathrm{bp}$, was found in the 477-bp sequence between PG3 and PG4. The significance of this repeat is not known, but it is noteworthy that the same repeat was also found in the related Arabidopsis region (Fig. 2).

High resolution genetic mapping (3000 gametes) showed that all of the identified rice genes recombined away from Rpg1 except PG2, which could not be mapped because of very poor hybridization with barley genomic DNA and lack of polymorphism. Thus, the PG2 gene remains as a potential candidate for Rpgl because it could not be eliminated.

\section{Discussion}

\section{Genome organization in rice}

Based on detailed physical mapping of the rice BAC 10$\mathrm{N}-24$, the sequenced $68 \mathrm{~kb}$ covers a region of about $90 \mathrm{~kb}$. The 15 putative genes identified in this region represent a minimum of one gene per $6 \mathrm{~kb}$. Based on a genome size of $4.5 \times 10^{8} \mathrm{bp}$ and an estimated 24000 genes, an average of one gene per $20 \mathrm{~kb}$ has been calculated (Inoue et al. 1994). Since the analyzed region is near the telomere, it would be expected to have a higher than average gene/kb ratio, assuming that plant centromeric regions are primarily comprised of heterochromatin and therefore have reduced recombination and fewer functional genes (Moore et al. 1993). Remarkably, PG3 and PG4 are separated by only $0.5 \mathrm{~kb}$ and transcribed in different directions. Assuming that PG3 and PG4 are both functional genes, they either share a common promoter region, which directs transcription in an opposite orientation or have a promoter region in a portion of the other gene as suggested for Arabidopsis (Bevan et al. 1998).

Gene distribution was uneven in the region analyzed. In the sequenced Bam 33 contig, five putative genes were identified with four of them located in a $15-\mathrm{kb}$ region, but none in the adjacent $14-\mathrm{kb}$ region. The uneven gene distribution phenomenon may also hold true for the syntenic barley region. This is indicated by a very high recombination and low physical/genetic distance ratio proximal to $R p g l$ and a very low recombination and high physical/genetic distance ratio distal to Rpgl (unpublished data). Genes per se have been suggested to be the preferential sites for recombination (Civardi et al. 1994).

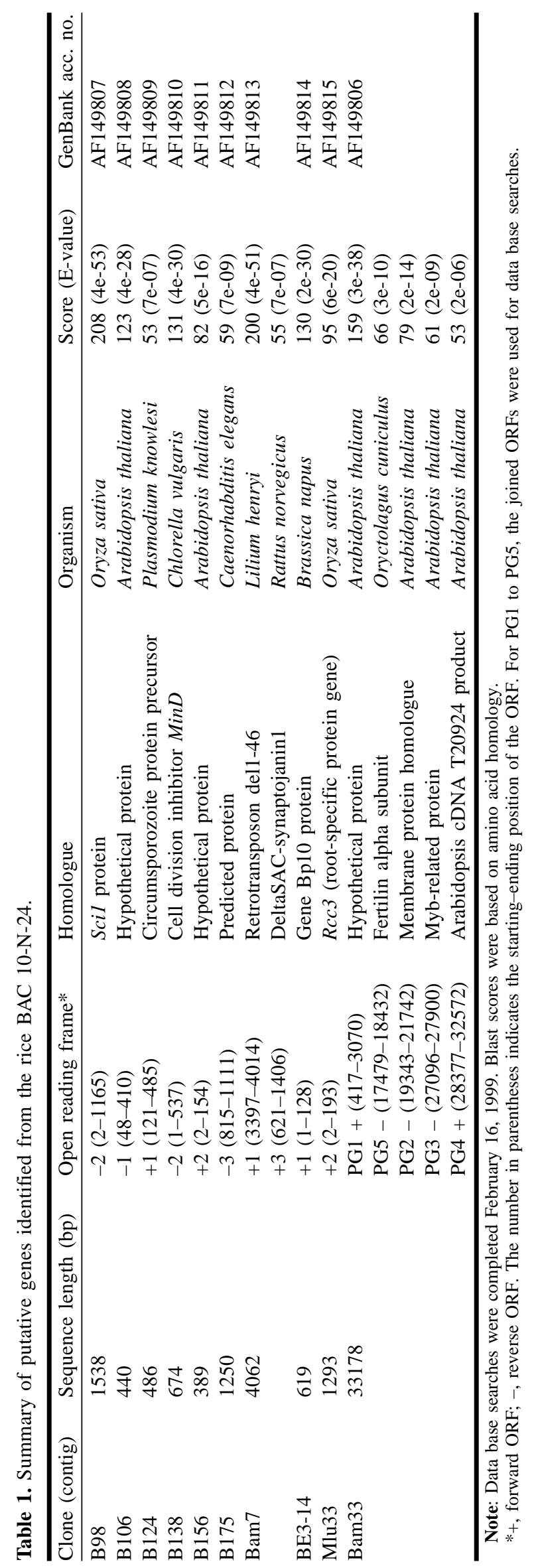

(C) 1999 NRC Canada 
Fig. 1. Comparative physical maps of rice and Arabidopsis relative to a barley genetic map. The putative genes identified by sequencing of the contiguous 33-kb rice BAC 10-N-24 fragment were compared with similar Arabidopsis genes. All putative rice genes, except PG2, were located by high resolution (3000 gametes) mapping in barley. The bars with diagonal stripes indicate the putative gene ORFs. The horizontal arrows indicate the direction of transcription. The gene size in rice was calculated based on similarity with the Arabidopsis ORFs. There may be additional ORFs that are part of the genes, but which do not have sufficient similarity to the Arabidopsis ORFs to be identified. The solid circles on the rice BAC indicate the location of probes used for mapping in barley. The vertical lines with double arrows indicate the ORFs with amino acid sequence similarity between rice and Arabidopsis. There are three additional putative genes between the hypothetical protein and membrane protein homologue in Arabidopsis BAC ATFCA6. Arabidopsis BAC ATFCA6 and IG002N01 have GenBank accession nos. Z97341 and AF007269, respectively, and are from Arabidopsis chromosome 4.

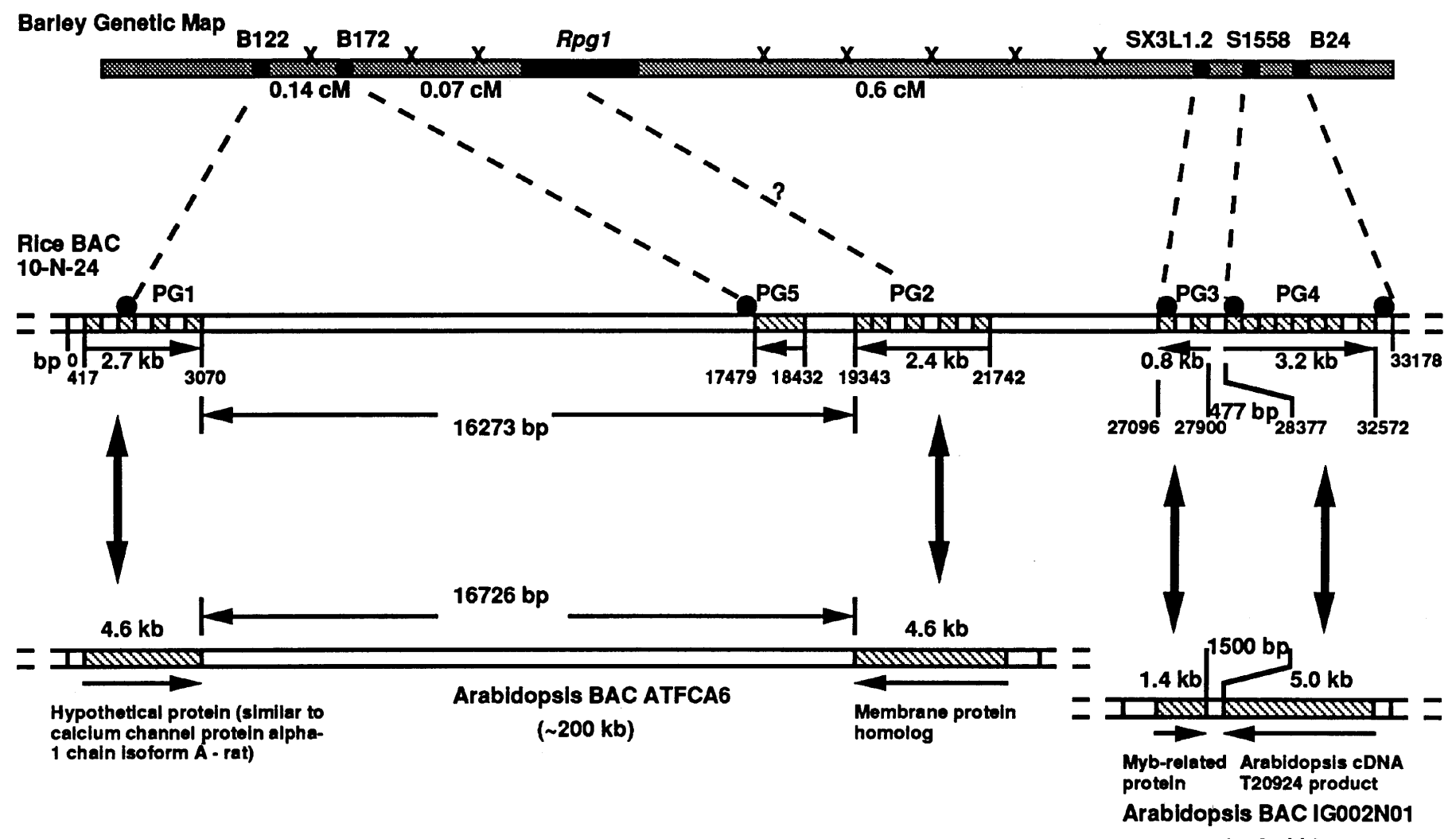

$(\sim 124 \mathrm{~kb})$

Is there a rice $\operatorname{Rpg} 1$ homologue?

Experiments described here were designed to identify a putative rice Rpgl homologue. High resolution genetic mapping in barley eliminated all of the identified rice genes as putative candidates for Rpgl, except the membrane proteinlike gene, PG2. Unfortunately, we have not been able to map this gene in barley because of poor hybridization and lack of polymorphism. The PG2 gene does not show sequence similarity to cloned $\mathrm{R}$ genes and thus would have to represent a novel disease resistance gene if it were an $R p g 1$ homologue.

It is perhaps more probable that Rpgl is the exception to the high degree of synteny between rice and barley in this region. An insertion event in barley or a deletion event in rice is a possibility. An intraspecies insertion and (or) deletion event has been described in Arabidopsis for the Rpml gene conferring resistance to the bacterium Pseudomonas syringae (Grant et al. 1995). Ectopic recombination of plant disease resistance genes has also been postulated due to the frequent nonsyntenic map locations for R-like genes mapped in different grass species (Leister et al. 1998). If the Rpgl gene is a member of the NBS-LRR class of disease resis- tance genes, it is clearly not present in the rice BAC, which includes the Rpgl flanking markers. An NBS-LRR R-like gene has been reported to cosegregate with Rpgl (Leister et al. 1998). However, this probe mapped ca. $0.5 \mathrm{cM}$ proximal to Rpgl in our segregating population (3000 gametes, unpublished data). Therefore, the question of whether rice has an Rpgl homologue and, if so, where is it located still remains to be determined.

\section{Comparison between rice and Arabidopsis}

Synteny between barley and rice in the barley stem rust resistance gene Rpg1 region, and some other regions, is well established (Han et al. 1998; Kilian et al. 1997). In our analysis of the rice Rpgl syntenous region, we were surprised to note that short regions appeared to be syntenous between rice and Arabidopsis. It is noteworthy that in addition to the sequence and position conservation of these genes, the genome regions in which the genes are embedded also appears to be related. This is particularly true for the PG3 and PG4 genes, which are separated by a short distance in both rice and Arabidopsis, but are transcribed in inverted orientation 
Fig. 2. Schematic representation of an inverted repeat conserved in rice and Arabidopsis. The figure is aligned on the rice genes PG3 and PG4 (not to scale).

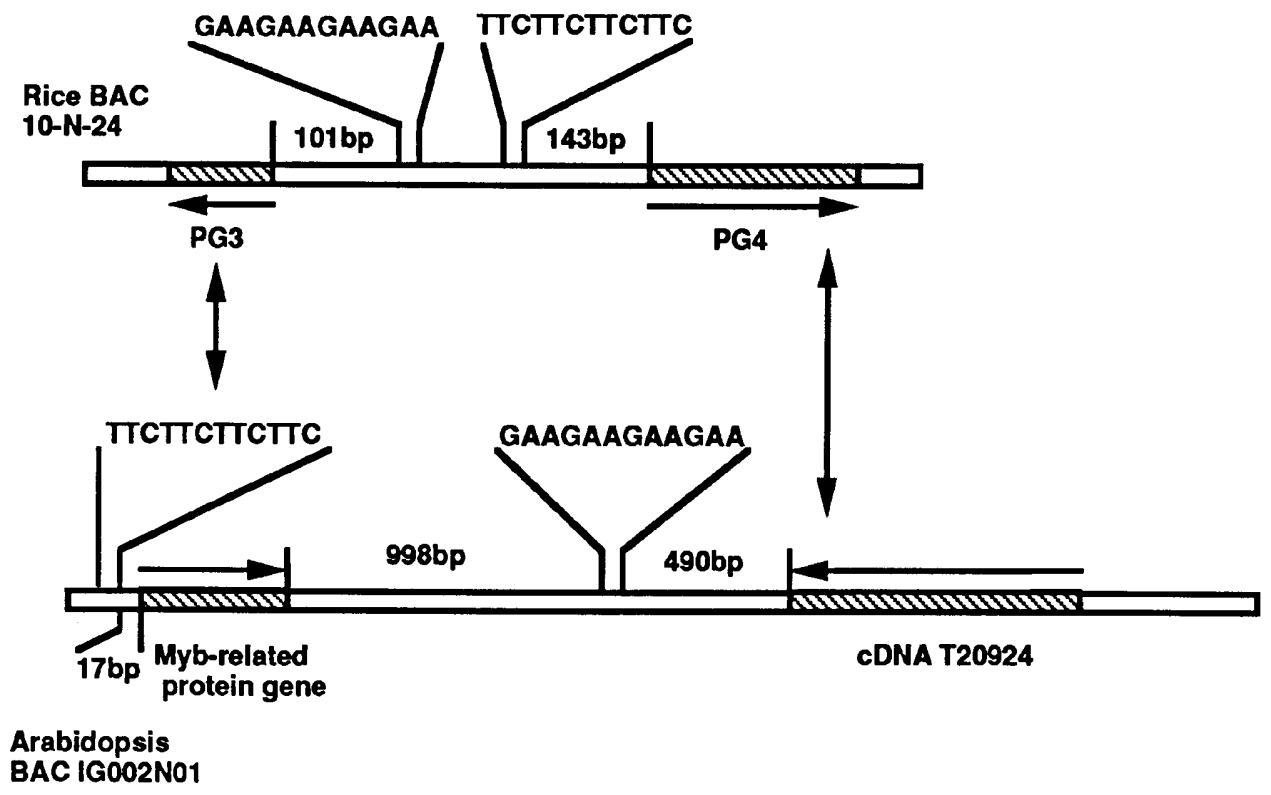

(Fig. 1). A careful examination of the sequence around the myb-related protein gene (PG3) in Arabidopsis revealed a short inverted repeat identical to that found in rice (Fig. 2). In Arabidopsis, the (GAA) $)_{4}$ repeat is between the mybrelated protein gene (similar to PG3) and T20924 gene product (similar to PG4), and (TTC) $)_{4}$ is 17 bp beyond the start codon, whereas in rice, both elements are between PG3 and PG4 (Fig. 2). These data indicate that the rice and Arabidopsis genomic regions containing PG3 and PG4 are related, but also have undergone considerable rearrangement(s). Distant evolutionary relationships have also been reported for mammals and invertebrates (Trachtulec et al. 1997).

The putative genes PG1 and PG2 are also separated by approximately the same distance in rice and Arabidopsis. In this case, however, the intervening sequences appear to be very different. In rice, the putative gene PG5 was found between PG1 and PG2, but an Arabidopsis homologue for this gene was not identified in data base searches. Since substantial sequence data for this region has been deposited, the PG5 homologue either does not exist or is found elsewhere in the Arabidopsis genome. In Arabidopsis, three putative genes are located between the PG1 and PG2 homologues. Homologues for these three putative Arabidopsis genes were not found in the sequenced rice BAC.

These data indicate an intriguing relationship between the order of some putative homologous genes on the rice and Arabidopsis chromosomes 6 and 4, respectively. However, they also indicate that extensive rearrangements have taken place resulting in the movement of some genes to unidentified positions and the reorganization of those that have remained linked. Are these observations attributable simply to chance or are they evolutionary relics maintained by yet undefined mechanisms of genome organization and evolution? Perhaps the answers will be found as the sequencing of the Arabidopsis and rice genomes proceeds.

\section{Acknowledgements}

This is scientific paper 9802-16 from the College of Agriculture and Home Economics Research Center, Washington State University, Pullman, Wash., project 4196. This study was supported by the United States Department of Agriculture-National Research Initiative plant research project grant 9600794 to A.K. We thank Dr. Pam Ronald, University of California-Davis, Calif., for providing the rice BAC 10N-24 and the members of the Rice Genome Project, Tsukuba, Japan for assistance and helpful discussions.

\section{References}

Altschul, S.F., Madden, T.L., Schaffer, A.A., Zhang, J.H., Zhang, Z., Miller, W., and Lipman, D.J. 1997. Gapped BLAST and PSIBLAST: A new generation of protein database search programs. Nucleic Acids Res. 25: 3389-3402.

Arumuganathan, K., and Earle, E.D. 1991. Nuclear DNA content of some important plant species. Plant Mol. Biol. Rep. 9: 208218.

Bevan, M., Bancroft, I., Bent, E., Love, K., Goodman, H., Dean, C., Bergkamp, R., Dirkse, W., Van Staveren, M., Stiekema, W., Drost, L., Ridley, P., Hudson, S.-A., Patel, K., Murphy, G., Piffanelli, P., Wedler, H., Wedler, E., Wambutt, R., Weitzenegger, T., Pohl, T.M., Terryn, N., Gielen, J., Villarroel, R., De Clerck, R., Van Montagu, M., Lecharny, A., Auburg, S., Gy, I., Kreis, M., Lao, N., Kavanagh, T., Hempel, S., Kotter, P., Entian, K.-D., Rieger, M., Schaeffer, M., Funk, B., MuellerAuer, S., Silvey, M., James, R., Montfort, A., Pons, A., Puigdomenech, P., Douka, A., Voukelatou, E., Milioni, D., Hatzopoulos, P., Piravandi, E., Obermaier, B., Hilbert, H., Dusterhoft, A., Moores, T., Jones, J.D.G., Eneva, T., Palme, K., Benes, V., Rechman, S., Ansorge, W., Cooke, R., Berger, C., Delseny, M., Voet, M., Volckaert, G., Mewes, H.-W., Klosterman, S., Schueller, C., and Chalwatzis, N. 1998. Analy- 
sis of $1.9 \mathrm{Mb}$ of contiguous sequence from chromosome 4 of Arabidopsis thaliana. Nature (London), 391: 485-488.

Civardi, L., Xia, Y., Edwards, K.J., Schnable, P.S., and Nikolau, B.J. 1994. The relationship between genetic and physical distances in the cloned al-sh2 interval of the Zea mays L. genome. Proc. Natl. Acad. Sci. U.S.A. 91: 8268-8272.

Devos, K., and Gale, M.D. 1997. Comparative genetics in the grasses. Plant Mol. Biol. 35: 3-15.

Grant, M.R., Godiard, L., Straube, E., Ashfield, T., Lewald, J., Sattler, A., Innes, R.W., and Dangl, J.L. 1995. Structure of the Arabidopsis RPM1 gene enabling dual specificity disease resistance. Science (Washington, D.C.), 269: 843-846.

Han, F., Kleinhofs, A., Ullrich, S.E., Kilian, A., Yano, M., and Sasaki, T. 1998. Synteny with rice: Analysis of barley malting quality QTL and rpg4 chromosome regions. Genome, 41: 373380.

Inoue, T., Zhong, H.S., Miyao, A., Ashikawa, I., Monna, L., Fukuoka, S., Miyadera, N., Nagamura, Y., Kurata, N., Sasaki, T., and Minobe, Y. 1994. Sequence-tagged sites (STSs) as standard landmarkers in the rice genome. Theor. Appl. Genet. 89: 728-734.

Kilian, A., Steffenson, B.J., Maroof, M.A.S., and Kleinhofs, A. 1994. RFLP markers linked to the durable stem rust resistance gene Rpg1 in barley. Mol. Plant-Microbe Interact. 7: 298-301.

Kilian, A., Kudrna, D.A., Kleinhofs, A., Yano, M., Kurata, N., Steffenson, B., and Sasaki, T. 1995. Rice-barley synteny and its application to saturation mapping of the barley Rpgl region. Nucleic Acids Res. 23: 2729-2733.

Kilian, A., Chen, J., Han, F., Steffenson, B., and Kleinhofs, A. 1997. Towards map-based cloning of the barley stem rust resistance genes Rpg1 and rpg4 using rice as an intergenomic cloning vehicle. Plant Mol. Biol. 35: 187-195.

Leister, D., Kurth, J., Laurie, D.A., Yano, M., Sasaki, T., Devos, K., Graner, A., and Schulze-Lefert, P. 1998. Rapid reorganization of resistance gene homologues in cereal genomes. Proc. Natl. Acad. Sci. U.S.A. 95: 370-375.

Moore, G., Abbo, S., Cheung, W., Foote, T., Gale, M.D., Koebner, R., Leitch, A., Leitch, I., Money, T., Stancombe, P., Yano, M., and Flavell, R. 1993. Key features of cereal genome organization as revealed by the use of cytosinemethylation sensitive restriction endonucleases. Genomics, 15: 472-482.

Saghai Maroof, M.A., Yang, G.P., Biyashev, R.M., Maughan, P.J., and Zhang, Q. 1996. Analysis of the barley and rice genomes by comparative RFLP linkage mapping. Theor. Appl. Genet. 92: 541-551.

Trachtulec, Z., Hamvas, R.M.J., Forejt, J., Lehrach, H.R., Vincek, V., and Klein, J. 1997. Linkage of TATA-binding protein and proteasome subunit $\mathrm{C} 5$ genes in mice and humans reveals synteny conserved between mammals and invertebrates. Genomics, 44: 1-7. 